\title{
PEMERIKSAAN KELAIKAN FUNGSI BANGUNAN GEDUNG RUMAH SAKIT
}

\author{
Syapril Janizar ${ }^{1}$, Felix Setiawan ${ }^{2}$, Edi Kurniawan ${ }^{3}$ \\ ${ }^{1,2}$ Dosen Teknik Sipil Universitas Winaya Mukti ${ }^{3}$ Alumni Teknik Sipil Universitas Winaya Mukti \\ Email : sjanizar@yahoo.com; felix.sehoey@gmail.com; edikurniawan@gmail.com
}

\begin{abstract}
Eligibility Function is a condition of a building that meets administrative and technical requirements in accordance with the specified building function. The feasibility of building functions is based on five component requirements: building layout, safety, health, comfort, convenience. Eligibility of the function of a building is valued based on administrative requirements and building technical requirements. The assessment method uses the Likert scale method and the Analytic Hierarchy Process (AHP) method. Weighting for building building requirements is not feasible $0 \%-33.33 \%$, feasible with repairs $33.34 \%-66.66 \%$ and $66.67 \%-100 \%$ worthy while for safety weighting $43 \%$, health $28 \%$, comfort $25 \%$ and $4 \%$ convenience.
\end{abstract}

Keywords: Feasibility, Building, safety

\begin{abstract}
ABSTRAK
Laik Fungsi adalah suatu kondisi Bangunan Gedung yang memenuhi persyaratan administratif dan persyaratan teknis sesuai dengan fungsi Bangunan Gedung yang ditetapkan. Pemeriksaaan kelaikan fungsi bangunan gedung dilakukan berdasarkan lima komponen persyaratan : tata bangunan, keselamatan, kesehatan, kenyamanan, kemudahan. Kelaikan fungsi suatu bangunan gedung di nilai berdasarkan persyaratan administrasi dan persyaratan teknis bangunan gedung. Metode dalam penilaian menggunakan metode skala likert dan metode Analytic Hierarchy Process (AHP). Pembobotan untuk persyaratan tata bangunan gedung yaitu tidak laik $0 \%-33,33 \%$, laik dengan perbaikan 33,34\% - 66,66\% dan laik 66,67\%-100\% sedangkan untuk pembobotan keselamatan $43 \%$, kesehatan 28\%, kenyamanan $25 \%$ dan kemudahan $4 \%$.
\end{abstract}

Kata Kunci: Laik, Fungsi, Bangunan

\section{PENDAHULUAN}

\section{Latar Belakang}

Bangunan gedung sebagai tempat manusia dalam melakukan kegiatannya, mempunyai peran yang sangat penting dalam pembentukan watak, perwujudan produktivitas, serta jati diri. Selain itu juga bangunan gedung berfungsi sebagai tempat manusia melakukan kegiatannya, baik untuk hunian atau tempat tinggal, keagamaan, usaha, sosial budaya maupun kegiatan khusus. Dalam menjamin kelangsungan dan peningkatan kehidupan serta penghidupan penghuninya serta mewujudkan bangunan gedung yang fungsional, andal, serta seimbang, serasi, dan selaras dengan lingkungannya, perlu adanya suatu pengaturan yang menjamin kelayakan bangunan gedung, terlebih bangunan tersebut bersifat publik yang mana melibatkan banyak orang didalamnya, sehingga kelaikan fungsi gedung sangat penting untuk menghindari hal - hal yang tidak diinginkan. Secara umum 
pemeriksaan kelaikan bangunan gedung dilakukan dengan Cara pengamatan visual kondisi fisik bangunan terhadap komponen Arsitektur, Struktur, Utilitas, Kebakaran dan pemenuhan fasilitas aksesibilitas bagi penyandang cacat.

Untuk pemeriksaan struktur beton pemeriksaan dilakukan dengan menggunakan hammer test. Untuk pemeriksaan instalasi bangunan pemeriksaan dilakukan dengan menggunakan alat pemantau suhu ruangan dan alat lainnya yang diperlukan. Setiap komponen pemeriksaan wajib disiapkan gambar rencana atau as built drawings untuk kebutuhan pemeriksaan dilapangan. Bila gambar yang dimaksud tidak tersedia, konsultan wajib membuat gambar sesuai dengan kebutuhan.

\section{Rumusan Masalah}

Permasalahan yang akan dibahas dalam penelitian ini adalah untuk melakukan pemeriksaan awal terhadap persyaratan administrasi maupun persyaratan teknis bangunan gedung.

\section{Batasan Masalah}

Permasalahan yang digunakan dilakukan pembatasan untuk memperjelas dan memudahkan dalam melakukan penelitian, yaitu:

1. Pengambilan data pada lapangan dilakukan dengan cara pengamatan visual dan pengukuran terhadap komponen arsitektur, struktur dan utilitas.

2. Pemeriksaan teknis bangunan terdiri dari :

\section{a. Arsitektur}

Pemeriksaan, arsitektur dilaksanakan pada finishing bangunan baik yang berada pada bagian dalam bangunan gedung, maupun yang berada pada bagian luar bangunan gedung, mencakup :

1) Fungsi bangunan gedung terhadap kesesuaian peruntukan lahan.

2) Interior, antara lain: finishing Lantai/selubung bangunan, dinding, pintu, plafond, jendela, kaca dan mebeul terpasang.

3) Eksterior, antara lain: finishing Binding, lantai, pagar, dan lingkungan pendukung.

b. Struktur

Evaluasi dilakukan terhadap sistem struktur, pondasi, kolom, balok, dinding, core, shear-wall, plafond dan atap.

c. Utilitas/Mekanikal dan Elektrikal

Evaluasi dilakukan terhadap sistem transportasi vertikal (STV), sistem transportasi vertical eskatator, sistem instalasi plambing (air bersih, air kotor dan limbah, dan air hujan), sistem instalasi listrik sistem Instalasi tata udara, sistem instalasi penangkal petir, sistem instalasi komunikasi dan tata suara, sistem pembuangan sampah, dan sistem BAS (Building Automatic System).

Persyaratan Pencegahan dan Penanggulangan Kebakaran, Evaluasi dilakukan pada sistem proteksi pasif dan aktif yang terdapat pada obyek bangunan gedung, termasuk pemeriksaan terhadap peralatan pemadam kebakaran, material insulator kebakaran.

3. Pengolahan data dilakukan dengan cara analisis terhadap data persyaratan administrasi dan persyaratan teknis bangunan gedung. 


\section{Tujuan Penelitian}

Penelitian ini mempunyai tujuan, yaitu: 1) menentukan pemeriksaan kelaikan bangunan gedung, 2) melakukan pengamatan visual, dan 3) mengidentifikasi persyaratan administrasi teknis dalam pemenuhan persyaratan terciptanya bangunan gedung yang layak sesuai yang diamanatkan dalam UU No. 28 Tahun 2002 tentang Bangunan Gedung dan sesuai dengan peraturan pelaksanaannya PP No. 36 Tahun 2005 di daerah.

\section{TINJAUAN PUSTAKA}

\section{Persyaratan Kelaikan Fungsi Bangunan Gedung}

Pemeriksaan pada proses penerbitan SLF bangunan gedung untuk menilai pemenuhan persyaratan administratif meliputi:

1. Kesesuaian data aktual (terakhir) dengan data dalam dokumen status hak atas tanah.

2. Kesesuaian data aktual (terakhir) dengan data dalam IMB, dan/atau dokumen status kepemilikan bangunan gedung yang semula telah ada/dimiliki. Status kepemilikan bangunan gedung.

3. Kepemilikan dokumen IMB.

Pemeriksaan pada proses perpanjangan SLF bangunan gedung untuk menilai pemenuhan persyaratan administratif meliputi:

1. Kesesuaian data aktual dan/atau adanya perubahan dalam dokumen status kepemilikan bangunan gedung berdasarkan pada perubahan kepemilikan;

2. Kesesuaian data aktual (terakhir) dan/atau adanya perubahan dalam dokumen status kepemilikan tanah; dan

Kesesuaian data aktual (terakhir) dan/atau adanya perubahan data dalam dokumen IMB berdasarkan antara lain adanya pemecahan IMB atas permohonan pemilik.

\section{Pemenuhan Persyaratan Teknis Bangunan Gedung}

Pemeriksaan dan pengujian pada proses penerbitan SLF bangunan gedung untuk menilai pemenuhan persyaratan teknis meliputi:

1. Kesesuaian data aktual (terakhir) dengan data dalam dokumen pelaksanaan konstruksi bangunan gedung termasuk as built drawings, pedoman pengoperasian dan pemeliharaan/perawatan bangunan gedung, peralatan serta perlengkapan mekanikal dan elektrikal bangunan gedung (manual), dan dokumen ikatan kerja;

2. Pengujian/test di lapangan (on site) dan/atau di laboratorium untuk aspek keselamatan, kesehatan, kenyamanan, dan kemudahan, pada struktur, peralatan, dan perlengkapan bangunan gedung, serta prasarana bangunan gedung pada komponen konstruksi atau peralatan yang memerlukan data teknis yang akurat. Pengujian/test dilakukan sesuai dengan pedoman teknis dan tata cara pemeriksaan kelaikan fungsi bangunan gedung.

Pemeriksaan dan pengujian pada proses perpanjangan SLF bangunan gedung untuk menilai pemenuhan persyaratan teknis meliputi:

1. Kesesuaian data aktual (terakhir) dengan data dalam dokumen laporan hasil pemeriksaan berkala, laporan pengujian struktur, peralatan, dan 
perlengkapan bangunan gedung, serta prasarana bangunan gedung, laporan hasil perbaikan dan/atau penggantian pada kegiatan perawatan, termasuk adanya perubahan fungsi bangunan gedung, intensitas, arsitektur bangunan gedung, dan dampak lingkungan yang ditimbulkan;

2. Pengujian/test di lapangan (on site) dan/atau di laboratorium untuk aspek keselamatan, kesehatan, kenyamanan dan kemudahan, pada struktur, peralatan dan perlengkapan bangunan gedung, prasarana bangunan gedung pada struktur, komponen konstruksi bangunan gedung dan peralatan yang memerlukan data yang akurat, termasuk adanya perubahan fungsi bangunan gedung, peruntukan dan intensitas, arsitektur bangunan gedung, serta dampak lingkungan yang ditimbulkan;dan

\section{METODOLOGI PENELITIAN}

Penelitian dilakukan pada dengan mengambil bangunan jenis rumah sakit. Berikut ini merupakan bagan alir pemeriksaan teknis bangunan gedung yang didasarkan Peraturan Menteri Pekerjaan Umum dan Perumahan Rakyat Republik Indonesia Nomor 27/PRT/M/2018 tentang Sertifikat Laik Fungsi Bangunan Gedung dan Peraturan Menteri Pekerjaan Umum dan Perumahan Rakyat Republik Indonesia Nomor 11/PRT/M/2018 tentang Tim Ahli Bangunan Gedung, Pengkaji Teknis, dan Penilik Bangunan.

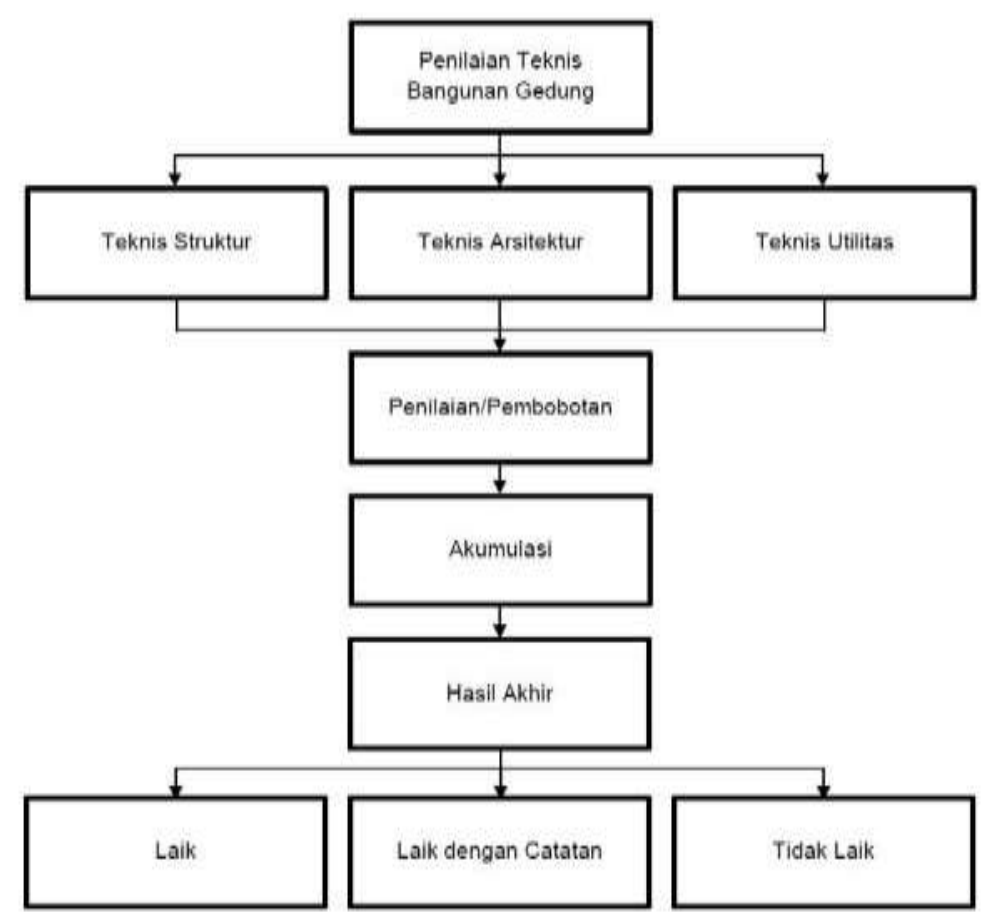

Tabel 3.1 Diagram Alir Pemeriksaan Teknis Bangunan Gedung

Dalam melakukan penilaian untuk persyaratan tata bangunan yang terdapat 3 kategori penilaian, yaitu:

1. Laik

2. Laik dengan Catatan Perbaikan 
3. Tidak Laik

Untuk mengetahui range dari kelaikan bangunan gedung makan dilakukan perhitungan dengan metode skala likert. Sebelum dilakukan penilaian, terlebih dahulu dilakukan pembobotan menggunakan metode analisis hirarki proses (AHP) terhadap keempat aspek yang dinilai antara lain keselamatan, kesehatan, kenyamanan dan kemudahan.

\section{ANALISIS DAN PEMBAHASAN}

\section{Persyaratan Administrasi Bangunan Gedung}

Persyaratan administrasi yang harus dilengkapi untuk memenuhi persyaratan kelaikan fungsi bangunan gedung adalah sebagai berikut:

Tabel 4.1 Persyaratan Administrasi BG Rumah Sakit

No

Persyaratan
Administrasi

1. Status Hak Atas Tanah

2. Status Kepemilikan

Bangunan gedung

Dokumen IMB beserta

3. lampiran rencana teknis
Hasil

Pemeriksaan

Ada/Tidak

Ada/Tidak

Ada/Tidak

\section{Keterangan}

Berdasarkan acuan dari Buku yang diterbitkan oleh Pemerintah zetempat

Nomor IMB yang dikeluarkan Pemerintah setempat

Sumber : Analisis 2020

\section{Persyaratan Teknis Bangunan Gedung}

Pemeriksaan Persyaratan Tata Bangunan Gedung

Dalam penilaian kelaikan bangunan gedung pada persyaratan tata bangunan gedung, terdapat 3 nilai yaitu Laik, Terdapat Catatan Perbaikan, dan Tidak Laik. Untuk mengetahui range dari kelaikan bangunan maka selanjutnya dilakukan perhitungan menggunakan skala likert. Hasil perhitungan tersebut adalah sebagai berikut:

- Laik

: $66,67 \%-100 \%$

- Laik dengan Catatan

: $66,66 \%-33,34$

- Tidak laik $: 33,33 \%-0 \%$ 
Tabel 4.2 Penilaian Kesesuaian Tata Bangunan Gedung

\begin{tabular}{|c|c|c|c|c|c|c|c|}
\hline $\mathrm{NQ}$ & AIFETENatay & 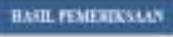 & Finguts: & No & 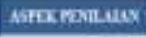 & mitastices & 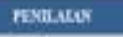 \\
\hline 1 & \multicolumn{3}{|l|}{ Nernatas Dageren fithes } & 4 & \multicolumn{3}{|c|}{ 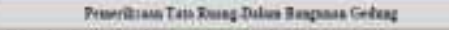 } \\
\hline $1-1$ & Fequi Buppair intas & Seen & 3 & 4 & 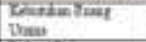 & Sent & 了 \\
\hline 1.6 & 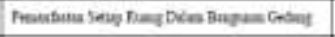 & lestis & 2 & 4 & 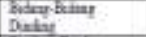 & Sear & 3 \\
\hline 1-5 & 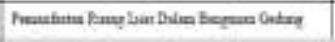 & This Sera & 1 & is & $\begin{array}{l}\text { Dhatapontar } \\
\text { Penisal }\end{array}$ & Senai & 3 \\
\hline 2 & \multicolumn{3}{|l|}{ 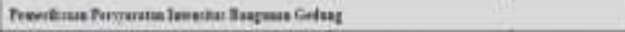 } & 4 & Pawkelat & Ime & 1 \\
\hline $1-1$ & femat Lanti fiapan & $\operatorname{ten}$ & 3 & is & Taxt Rany & Intix & 1 \\
\hline 2.6 & 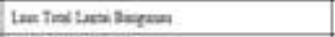 & That Sense & 1 & $H$ & 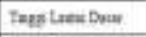 & Inat & 3 \\
\hline $2+6$ & Las Letui Dear Regane & Tae Sens & 1 & 4 & 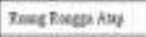 & $\operatorname{sen}$ & b \\
\hline 1.4 & Retupun Lingea & tens & 3 & At & Fexplantix & $\operatorname{sen}$ & 3 \\
\hline $2+4$ & 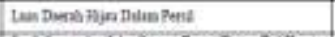 & That fora & 1 & 4 & Teuta langlisagt & $\operatorname{sen}$ & 3 \\
\hline $2, t$ & 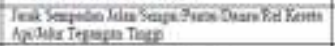 & Tatak lens: & 1 & 1 & \multicolumn{3}{|c|}{ 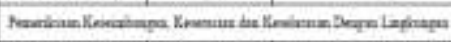 } \\
\hline $2 \cdot t$ & 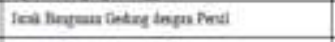 & inse & 1 & 3.0 & 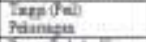 & Sente & 1 \\
\hline $1+t$ & Trei Aanr Bangen & sole & 3 & 5:-3 & 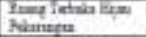 & Thie Sesau & 1 \\
\hline 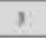 & \multicolumn{3}{|l|}{ 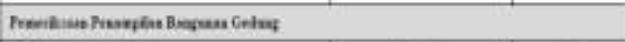 } & $5-t$ & 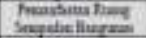 & 7at Sen: & 1 \\
\hline 3-s & 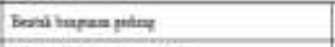 & Sens & 2 & $3-4$ & $\begin{array}{l}\text { Dundajen } \\
\text { Beruas }\end{array}$ & Ithit berm & 1 \\
\hline $3-b$ & Fond bed lesgan joles & Sour & 2 & $5-e$ & De Tues & Sexes & 1 \\
\hline ine & tapist tugrean gotent & $\operatorname{los}$ & 2 & $5 \cdot t$ & 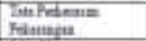 & Thas Seral & 1 \\
\hline 3.6 & 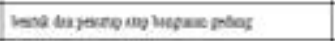 & Sous & 2 & $2-1$ & 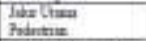 & The seal & 1 \\
\hline $3-\pi$ & 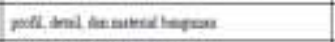 & Sees: & 3 & 5-4 & 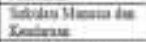 & Sone & b \\
\hline $9-1$ & hen fil rovpqup duspe & Seres & 2 & $5+i$ & 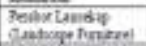 & $\operatorname{ser}$ & 1 \\
\hline \multirow[t]{2}{*}{$3-5$} & burmethesturgan. & Ses: & 2 & $9-1$ & 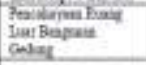 & Sout & ; \\
\hline & & & & $\$ 2.8$ & Produe flpopt: & souk & 3 \\
\hline
\end{tabular}

Sumber : Hasil Analisis 2020

Berdasarkan hasil penilaian tersebut maka diperoleh persentase penilain sebesar $\mathbf{7 2 , 8 1} \%$, sesuai dengan perhitungan skala likert yang telah dilakukan sebelumnya maka persyaratan tata bangunan gedung Rumah Sakit X termasuk dalam kategori laik.

\section{Pemeriksaan Persyaratan Keselamatan}

Dalam penilaian kelaikan bangunan gedung pada pemeriksaan persyaratan keselamatan, terdapat 3 nilai yaitu Laik, Terdapat Catatan Perbaikan, dan Tidak Laik. Untuk mengetahui range dari kelaikan bangunan maka selanjutnya dilakukan perhitungan menggunakan skala likert. Hasil perhitungan tersebut adalah sebagai berikut:

- Laik

$: 43 \%-28,7 \%$

- Laik dengan Catatan

$: 28,6 \%-14,4 \%$

- Tidak laik

$$
: 14,3 \%-0 \%
$$

Berikut ini merupakan hasil penilaian pemeriksaan persyaratan keselamatan bangunan gedung. 
Tabel 4.3 Penilaian Kesesuaian Keselamatan Bangunan Gedung
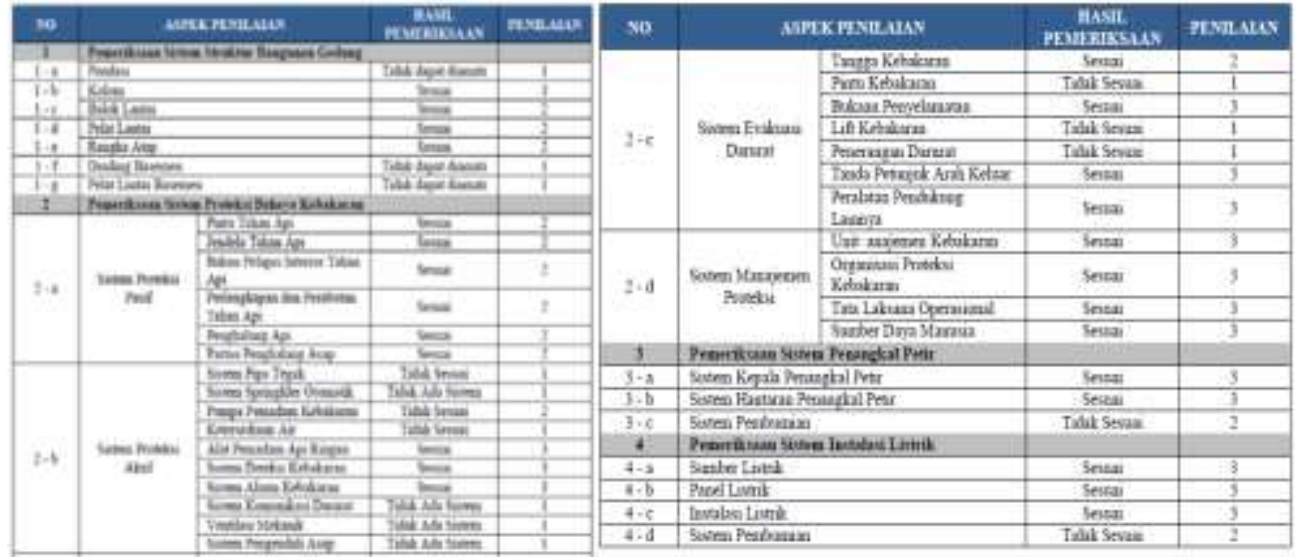

Sumber : Hasil Analisis 2020

Berdasarkan hasil penilaian tersebut maka diperoleh persentase penilain sebesar 31,61 \%, sesuai dengan perhitungan skala likert yang telah dilakukan sebelumnya maka penilaian berdasarkan aspek persyaratan keselamatan termasuk dalam kategori laik.

\section{Pemeriksaan Persyaratan Kesehatan}

Dalam penilaian kelaikan bangunan gedung pada pemeriksaan persyaratan kesehatan, terdapat 3 nilai yaitu Laik, Terdapat Catatan Perbaikan, dan Tidak Laik. Untuk mengetahui range dari kelaikan bangunan maka selanjutnya dilakukan perhitungan menggunakan skala likert. Hasil perhitungan tersebut adalah sebagai berikut:

- Laik

- Laik dengan Catatan

- Tidak laik

$$
\begin{aligned}
& : 28 \%-18,7 \% \\
& : 18,6 \%-9,4 \% \\
& : 9,3 \%-0 \%
\end{aligned}
$$

\begin{tabular}{|c|c|c|c|c|c|c|c|}
\hline No. & ASWE FENHAMY & 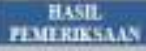 & PESHLALS & No & ASHE FEMLALA & 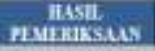 & FEMILA \\
\hline 1 & \multicolumn{3}{|l|}{ Saten Fupa pawail } & 4 & \multicolumn{3}{|c|}{ 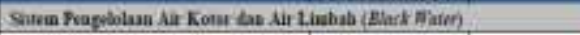 } \\
\hline $1-2$ & Ventlain Abm & Sesai & 3 & $4-2$ & Peabran Sarider & Serai & 2 \\
\hline $1-0$ & Ventiau Mabinil & Senui & 3 & $4-b$ & Inataluai 1alet Oathet & Sorat & 2 \\
\hline $1-\varepsilon$ & Solea Penplontivia Cdas & Sewai & 3 & $4-6$ & Siliest Jaringut Pesihuapos & Shati & 3 \\
\hline 2 & \multicolumn{3}{|l|}{ Sítem Peucalargaa } & $4-d$ & Siden Penurupupon dea Prepolaten & Serrat & 3 \\
\hline $2-\alpha$ & Powaluy yain Alani & Serai & 3 & 3 & \multicolumn{3}{|l|}{ 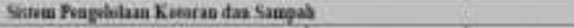 } \\
\hline $2 \cdot b$ & Pexcalyyan Buabe Artifials! & Sevai & 3 & 5-a & Iniet Penibuages & Servet & 2 \\
\hline $2 \cdot c$ & 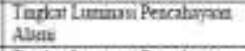 & Senmai & 3 & $5 \cdot 6$ & Peapranas Senestan datim Peral & Serwai & 2 \\
\hline $2-4$ & 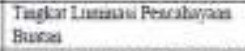 & Secait & 3 & $5-c$ & Pentoban datut Penil & Sevati & 2 \\
\hline 3 & \multicolumn{3}{|c|}{ Sirten Peryydiaas Atr Beruh Mimin } & 4 & \multicolumn{3}{|l|}{ 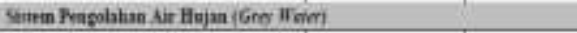 } \\
\hline 3-a & Sureter Air Bena Murau & Sescait & 2 & $6-2$ & 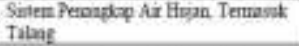 & Sesial & 2 \\
\hline $3-6$ & 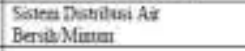 & 5 enait & 2 & $6-b$ & 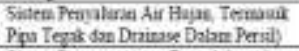 & Sentat & 5 \\
\hline 3-c & Jusinas As Berah Stmum & Senai & 2 & $6-c$ & 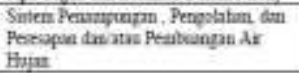 & Senat & 2 \\
\hline $3 \cdot d$ & Debe Ar Benik Mirum & Semai & 2 & & & & \\
\hline
\end{tabular}

Tabel 4.4 Penilaian Kesesuaian Kesehatan Bangunan Gedung

Sumber : Hasil Analisis 2020 
Berdasarkan hasil penilaian tersebut maka diperoleh persentase penilain sebesar 23,11 \%, sesuai dengan perhitungan skala likert yang telah dilakukan sebelumnya maka penilaian berdasarkan aspek persyaratan kesehatan termasuk dalam kategori laik.

\section{Pemeriksaan Persyaratan Kenyamanan}

Dalam penilaian kelaikan bangunan gedung pada pemeriksaan persyaratan kenyamanan, terdapat 3 nilai yaitu Laik, Terdapat Catatan Perbaikan, dan Tidak Laik. Untuk mengetahui range dari kelaikan bangunan maka selanjutnya dilakukan perhitungan menggunakan skala likert. Hasil perhitungan tersebut adalah sebagai berikut:

- Laik

- Laik dengan Catatan

- Tidak laik

$$
\begin{aligned}
& : 25 \%-16,7 \% \\
& : 16,6 \%-8,4 \% \\
& : 8,3 \%-0 \%
\end{aligned}
$$

Berikut ini merupakan hasil penilaian pemeriksaan persyaratan kenyamanan

\begin{tabular}{|c|c|c|c|}
\hline No & ASPEK PENIWAIAN & $\begin{array}{l}\text { MASIL } \\
\text { PKMIIRIKSAMN }\end{array}$ & PENIIAEAN \\
\hline 1 & \multicolumn{3}{|c|}{ Pemeriksaan Ruang Gerak dalaun Bangunan } \\
\hline $1-a$ & $\begin{array}{l}\text { Jumlah Pengguma atau Batas } \\
\text { Okupansi }\end{array}$ & Sestai & 3 \\
\hline $1+b$ & Kapasitas dan Tata Letak Perabol & Sesuai & 2 \\
\hline 2 & \multicolumn{3}{|c|}{ Pemenksaan Kondis Cdara datam Ruang } \\
\hline $2 \cdot 3$ & Temperatur Ruang & Sevuai & 3 \\
\hline $2+\mathrm{b}$ & Kelembaban Ruang & Sesuai & 3 \\
\hline 3 & \multicolumn{3}{|c|}{ Pemeriksaas Pasdasgan Dan das Kedalam Bangunan Geduв } \\
\hline $3 * a$ & $\begin{array}{l}\text { Pandangan dari Dalam Ruane ke } \\
\text { Luar Banguuaa }\end{array}$ & Sesitai & 3 \\
\hline $3 \cdot b$ & Pandangan dari Luar Kuang & Sesuai & 3 \\
\hline+ & \multicolumn{3}{|c|}{ Pemeriksaan KondisiKebisingan dalam Banzunan Gedung } \\
\hline $4-a$ & Tugkat Kebisiugan & Sestuai & 3 \\
\hline
\end{tabular}
bangunan gedung.

Tabel 4.5 Penilaian Kesesuaian Kenyamanan Bangunan Gedung

Sumber : Hasil Analisis 2020

Berdasarkan hasil penilaian tersebut maka diperoleh persentase penilain sebesar $23,81 \%$, sesuai dengan perhitungan skala likert yang telah dilakukan sebelumnya maka penilaian berdasarkan aspek persyaratan kenyamanan termasuk dalam kategori laik.

\section{Pemeriksaan Persyaratan Kemudahan}

Dalam penilaian kelaikan bangunan gedung pada pemeriksaan persyaratan kemudahan, terdapat 3 nilai yaitu Laik, Terdapat Catatan Perbaikan, dan Tidak Laik. Untuk mengetahui range dari kelaikan bangunan maka selanjutnya dilakukan perhitungan menggunakan skala likert. Hasil perhitungan tersebut adalah sebagai berikut:

- Laik

- Laik dengan Catatan

- Tidak laik

$$
\begin{aligned}
& : 4 \%-2,7 \% \\
& : 2,6 \%-1,4 \% \\
& : 1,3 \%-0 \%
\end{aligned}
$$


Tabel 4.6 Penilaian Kesesuaian Kemudahan Bangunan Gedung

\begin{tabular}{|c|c|c|c|}
\hline No & ASPEK PENILALAN & $\begin{array}{c}\text { HASIL } \\
\text { PEMERIKSAAN }\end{array}$ & PENILAIAN \\
\hline 1 & \multicolumn{3}{|c|}{ Pemeriksaan Sarana Hubungan Horizontal } \\
\hline $1-a$ & Kondisi Bukaan Pintu & Sestai & 3 \\
\hline $1-b$ & Kondisi Koridor & Sesuai & 3 \\
\hline 2 & \multicolumn{3}{|c|}{ Pemeriksaan Sarana Hubungan Vertikal } \\
\hline $2-\mathrm{a}$ & Tangga & Sestuai & 2 \\
\hline $2 \cdot \mathrm{b}$ & Ram & Sesuai & 3 \\
\hline 3 & \multicolumn{3}{|c|}{ Pemeriksaan Kelengkapan Prasarana dan Sarana Bangunan Gedung } \\
\hline $3-a$ & Toilet & Sesuai & 2 \\
\hline $3-b$ & Fasilitas Parkir & Sestai & 3 \\
\hline \multicolumn{2}{|c|}{ SumbernuasiliAnalisis 2020} & Sestuai & 3 \\
\hline $3-d$ & Tempat Sampah & Sesuai & 3 \\
\hline $3-\mathrm{e}$ & Sistem Komminikasi & sesuai & 3 \\
\hline $3 \cdot f$ & Sistem Informasi & sesuai & 3 \\
\hline
\end{tabular}

Berdasarkan hasil penilaian tersebut maka diperoleh persentase penilain sebesar $3,73 \%$, sesuai dengan perhitungan skala likert yang telah dilakukan sebelumnya maka penilaian berdasarkan aspek persyaratan kemudahan termasuk dalam kategori laik.

\section{KESIMPULAN}

\section{Kesimpulan}

Penilaian terhadap kelaikan bangunan gedung dilakukan berdasarkan pemeriksaan persyaratan administrasi bangunan gedung dan persyaratan teknis bangunan gedung. Berdasarkan hasil penilaian yang dilakukan, terdapat beberapa catatan perbaikan yang harus diperbaiki. Maka bangunan gedung Rumah Sakit X dapat dikategorikan Laik dengan Catatan Perbaikan.

\section{DAFTAR PUSTAKA}

Undang - Undang Republik Indonesia No. 28 tahun 2002 Tentang Bangunan Gedung.

Peratruran Menteri Pekerjaan Umum Nomor 29/PRT/M/2006 tentang Pedoman Persyaratan Teknis Bangunan Gedung.

Peraturan Menteri Pekerjaan Umum dan Perumahan Rakyat Republik Indonesia Nomor 11/PRT/M/11/2018 tentang Tim Ahli Bangunan Gedung, Pengkaji Teknis dan Penilik Bangunan.

Peraturan Menteri Pekerjaan Umum dan Perumahan Rakyat Republik Indonesia Nomor 27/PRT/M/2018 tentang Sertifikat Laik Fungsi Bangunan Gedung. SNI 0225:2011 tentang Persyaratan Umum Instalasi Listrik 2011 (PUIL 2011). SNI 03

- 1746 - 2000 tentang Tata Cara Perencanaan dan Pemasangan Sarana Jalan

Keluar untuk Penyelamatan Terhadap Bahaya Kebakaran pada Bangunan Gedung.

SNI 03 - 2396 - 2001 tentang Tata Cara Perancangan Sistem Pencahayaan Alami pada Bangunan Gedung.

SNI 03 - 6197 - 2000 tentang Konservasi Energi pada Sistem Pencahayaan.

SNI 03 - 6572 - 2001 tentang Tata Cara Perancangan Sistem Ventilasi dan Pengkondisian Udara pada Bangunan Gedung. 
SNI 03-6575-2001 tentang Tata Cara Perancangan Sistem Pencahayaan Buatan pada Bangllllan Gedung.

SNI 03-7015-2004 tentang Sistem Proteksi Petir pada Bangllllan Gedllllg.

SNI 03 -7065-2005 tentang Tata Cara Perencanaan Sistem Plambing.

SNI 2847:2013 tentang ersyaratan Beton StrukturallUltuk Bangunan Gedllllg. 